\title{
Proteína C-reactiva ultrasensible en pacientes con y sin periodontitis crónica severa generalizada
}

\section{Ultra-sensible C-reactive protein in patients with and without chronic severe generalized periodontitis}

\author{
DE FREITAS RÊGO BEZERRA C* \\ LUZ DE AQUINO AR** \\ COSTA DE LIMA $\mathbf{K} * * *$ \\ DA FONTE PORTO CARREIRO $\mathrm{A} * * * *$
}

\begin{abstract}
De Freitas Rêgo Bezerra C, Luz de Aquino AR, Costa de Lima K, da Fonte Porto Carreiro A. Proteína C-reactiva ultrasensible en pacientes con y sin periodontitis crónica severa generalizada. Av Periodon Implantol. 2009; 21, 3: 145-155.
\end{abstract}

\section{RESUIMEN}

Introducción: La proteína C-reactiva ultrasensible (PCR-US) constituye un mediador inflamatorio utilizado como predictor del riesgo cardiovascular que viene siendo investigado como factor indicativo de la relación entre enfermedades cardiovasculares y periodontales. Este trabajo tuvo como objetivo comparar los niveles séricos de proteína C-reactiva entre pacientes con y sin periodontitis crónica severa generalizada.

Material y métodos: Se realizó un estudio seccional, utilizando una muestra de 60 pacientes, siendo 29 participantes con enfermedad periodontal (Grupo I) y 31 sin enfermedad (Grupo II). Como criterios de inclusión fueron seleccionados pacientes con diagnóstico de periodontitis crónica severa generalizada. La investigación constó de dos etapas, clínica y bioquímica. La clínica consistió en el examen periodontal y la bioquímica en la recogida de sangre para determinación de los niveles de PCR-US y un hemograma.

Resultados: El grupo con enfermedad periodontal presentó una media de 0,36 mg/dl, mientras el sin enfermedad de $0,17 \mathrm{mg} / \mathrm{dl}(\mathrm{p}=0,06 \mathrm{l})$. El riesgo cardiovascular para el grupo I fue clasificado como alto para $27,6 \%$ de los participantes y bajo para 72,4\%. En el grupo II, 6,45\% presentaban alto riesgo y $93,5 \%$ bajo riesgo, siendo esa relación estadísticamente significativa obtenida por el test de Fisher $(p=0,042)$, presentando uno OR=5,33; IC95\% $(1,02-27,4)$. Las variables interventores investigadas no presentaron asociación estadísticamente significativa con los niveles de PCR-US.

Conclusión: EL estudio indicó que pacientes portadores de periodontitis crónica severa generalizada no presentaron niveles séricos de PCR-US estadísticamente diferente de los pacientes sin enfermedad. La periodontitis actuó como factor asociado para la elevación de los niveles de la PCR-US, aunque con frágil asociación.

PALABRAS CLAVE: Proteína C-reactiva, periodontitis, cardiopatías.

\section{SUMIMARY}

Introduction: The high sensitivity C-reactive protein (hSCRP) constitutes an inflammatory mediator used as predictor of cardiovascular risk that comes being researched as indicative relation factor between cardiovascular and periodontal diseases. This work had the purpose of compare seric levels of C-reactive protein between patients with and without chronic severe generalized periodontitis.

Material and methods: A cross-sectional study was realized using a sample with 60 patients, being 29 participants carriers of periodontal diseases (Group I) and 31 without periodontal diseases (Group

* $\quad$ Mestre en Periodoncia. Universidad Federal de Rio Grande do Norte.

** Alumna del Mestrado en Periodoncia. Universidad Federal de Rio Grande do Norte.

*** Profesor Adjunto de Odontología Preventiva. Faculdad de Odontología de la Universidad Federal de Rio Grande do Norte.

**** Profesora Adjunta de Prótesis Total. Faculdad de Odontología de la Universidad Federal de Rio Grande do Norte.. 
II). As inclusion criteria were selected patients with diagnosis of chronic severe generalized periodontitis. The research consisted of two stages, clinc and biochemical. The stage was constituted of periodontal examination and the biochemist stage, of the blood collection for determination hsCRP levels and a hemogram.

Results: Periodontal disease group presented a average of $0,36 \mathrm{mg} / \mathrm{dL}$, while the group without disease presented $0,17 \mathrm{mg} / \mathrm{Dl}(\mathrm{p}=0,061)$. The cardiovascular risk for the group I was classified high for $27,6 \%$ of participants and low for $72,4 \%$ of them. In the group II, $6,45 \%$ presented high risk e $93,5 \%$ low risk, being this relation significant statistically gotten for Fisher's Test $(p=0,042)$ presenting OR $=5,33 ; \mathrm{IC}=95 \%(1,02-27,4)$. The independents variables researched do not presented significant statistically association with the levels of hsCRP.

Conclusion: The study indicated that despite of carriers patients of periodontal diseases do not present differents seric levels of hsCRP from the other group, the periodontal disease was considered as risk factor for hsCRP levels elevation.

KEY WORDS: C-reactive protein, periodontitis, cardiopathy.

Fecha de recepción: 10 de noviembre de 2008. Fecha de aceptación: 18 de noviembre de 2008.

\section{INTRODUCCIÓN}

Uno de los actuales paradigmas de la Periodoncia incluye la investigación de la posible relación existente entre la enfermedad periodontal y la cardiovascular, aunque el mecanismo exacto de enlace entre esas enfermedades todavía no esté totalmente aclarado (1). Se consideran dos hipótesis, una enfocada en la infección crónica que la periodontitis representa para el organismo, constituyendo una vía de acceso de microorganismos y endotoxinas; y la segunda hipótesis, que se basa en la estimulación de la liberación de mediadores inflamatorios por la enfermedad periodontal, los cuales se mantienen en niveles elevados en el organismo, originando la aterosclerosis (2-4).

En los últimos años se acumulan evidencias sobre el papel de la inflamación en la fisiopatogenia de la aterosclerosis, y en el surgimiento de eventos arterotrombóticos, determinando los cuadros de síndromes coronarios agudos (5). Así, es sabido que tanto en los procesos de arteriosclerosis como en la enfermedad periodontal se presentan componentes inflamatorios implicados (6).

La proteína C-reactiva (PCR) es una de las proteínas plasmáticas que aparecen en la fase aguda de la inflamación, siendo utilizada rutinariamente en la evaluación de pacientes con desórdenes inflamatorios de cualquier naturaleza (7). La PCR puede utilizarse como auxiliar en el diagnóstico, control terapéutico y segui- miento de diversas patologías, una vez que es un índice sensible de procesos inflamatorios resultado de infecciones, carcinomas, necrosis de los tejidos y operaciones $(8,9)$.

Actualmente existen evidencias que sugieren el uso de la proteína C-reactiva como un importante marcador de trastornos coronarios futuros (2, 3, 10-13). Según Corrêa y Burini (8), los niveles normales de PCR varían de población en población, encontrándose una variación en promedio de entre 0,25 y $0,5 \mathrm{mg} / \mathrm{dl}$. Con el empleo de métodos ultrasensible es posible detectar niveles de PCR a partir de 0,09 mg/dl.

Estudios recientes $(2-4,14,15)$ mostraron que un discreto aumento de la PCR ya se considera un factor de riesgo cardiovascular, independientemente de otros. La PCR puede utilizarse junto con otros indicadores ya conocidos y considerados como factores de riesgo como el tabaquismo, la obesidad, dislipidemia, hipertensión, diabetes, edad avanzada y sexo.

Además, las infecciones orales crónicas, en especial las que alcanzan los tejidos periodontales, vienen siendo indicadas como agentes que pueden contribuir al desencadenamiento de una respuesta inflamatoria sistémica debido a la relación existente entre las enfermedades periodontales y episodios inflamatorios (1619). Según Dasanayake (20) e Moutsopoulos (21), durante una infección periodontal, mediadores inflamatorios como la interleuquina-l (IL-1), el factor de 
necrosis tumoral, la (TNF- $\alpha$ ) y las prostaglandinas E2 (PGE2 ) dirigen la respuesta inflamatoria y estimulan la producción de proteína C-reactiva.

Por lo tanto se vuelve necesario investigar el papel de la enfermedad periodontal sobre los niveles de proteína C-reactiva. Es importante averiguar si esa respuesta inflamatoria ocasionada por la enfermedad es suficientemente intensa para ocasionar cambios significativos en los niveles séricos de la PCR, comparándolo con personas exentas sin enfermedad periodontal. Así, el objetivo del presente estudio ha sido comparar los niveles séricos de la proteína C-reactiva ultrasensible (PCR-US) entre pacientes con periodontitis crónica severa generalizada y sin periodontitis.

\section{MATERIAL Y MÉTODOS}

La presente investigación se trata de un estudio seccional realizado en la clínica de Periodoncia del Departamento de Odontología de la Universidad Federal de Río Grande do Norte, en el periodo de Noviembre de 2005 a Diciembre de 2006. La muestra constó de 62 pacientes, de los cuales 31 eran enfermos con periodontitis crónica severa generalizada (Grupo I) y 31 pacientes sin periodontitis (Grupo II).

El principal criterio de inclusión utilizado en el reclutamiento de los participantes para ambos grupos fue la no existencia de ningún tipo de enfermedad o condición sistémica. Para el grupo I se seleccionaron pacientes con diagnóstico de periodontitis crónica severa generalizada. De acuerdo con Kinane y Lindhe (22), sus características clínicas incluyen intensa inflamación gingival (alteraciones de memoria y textura), sangrado al sondeo en el área del surco gingival, disminución de la resistencia de los tejidos periodontales al sondeo (bolsa periodontal), pérdida de inserción gingival y del hueso alveolar. Además de presentar al menos $30 \%$ de la dentición acometida por la enfermedad y presencia de dientes con nivel de inserción mayor o igual que $5 \mathrm{~mm}$. Esos participantes no podían haber recibido tratamiento periodontal previo por un periodo de 6 meses.

Para el grupo II, la selección de los participantes se realizó a través de la inclusión de pacientes sin pérdida de inserción periodontal, y que no presentasen alteración en los tejidos de sustentación del periodonto. Además, debían tener edad y sexo semejantes al grupo con enfermedad periodontal.
Fueron excluidos del experimento, para ambos grupos, aquellos individuos que presentaron ciertas condiciones sistémicas como enfermedades cardiovasculares, respiratorias, renales y patologías malignas, así como historia de cualquier otra infección sistémica o tratamiento con cualquier medicación que pudiese interferir en los niveles séricos de la proteína C-reactiva, con histórico de infarto o accidente cerebrovascular, así como fumadores, diabéticos, gestantes y lactantes. Estas informaciones fueron obtenidas a través de cuestionario aplicado durante la anamnesis, con objetivo de disminuir el número de variables que pudiesen llevar al enmascaramiento de los resultados.

Además de esto, también fueron excluidos del experimento aquellos pacientes que presentaron alteraciones en la serie blanca del hemograma, sugiriendo un cuadro de infección y/o inflamación.

La investigación constó de dos etapas, una clínica y otra bioquímica. Inicialmente se realizó el examen periodontal completo, incluyendo sondeo de todos los elementos dentarios y obtención del índice de placa (IP) y índice gingival (IG). Previamente a las dos etapas, se aplicó un cuestionario a cada individuo, con el objetivo de tomar datos relacionados a la exposición a los indicadores de riesgo, tanto para la enfermedad cardiovascular como para la periodontal. Se registró la condición sistémica y la gingival a través de las respuestas obtenidas en la anamnesis.

La investigación se realizó por un único examinador, siendo necesaria la realización de un proceso de calibración con la finalidad de comparar el grado de concordancia/discordancia de los datos obtenidos en el examen periodontal. El coeficiente kappa fue obtenido para la variable profundidad de sondeo por tratarse de una variable con alto grado de subjetividad presentando un valor de 0,91 quedando así comprobada la reproducibilidad del examinador.

Para la realización del examen periodontal fueron utilizados espejo plano $n^{\circ} 5$ y sonda periodontal manual milimetrada Goldman/Fox Williams de la Trinity®. El sondeo fue realizado en seis sitios, tres bucales (mesobucal, bucal y disto-bucal) y tres por lingual o palatino (meso-lingual o meso-palatino, lingual o palatino y lingual distal o palatino distal).

La amplitud de mucosa queratinizada fue obtenida a través de la medida (en milímetros) entre el margen gingival hasta la unión mucogingival en todos los elementos dentarios presentes en la cavidad oral. Para la 
cuantificación de la movilidad dentaria se utilizaron los siguientes parámetros: movilidad observada en el sentido vestíbulo-lingual/palatino (Grado 1), movilidad evidenciada en el sentido vestíbulo-lingual/palatino y también en el mesiodistal (Grado 2) y movilidad observada en los sentidos anteriormente citados añadido al movimiento en el sentido ocluso-cervical (Grado 3$)$.

El índice de placa (IP) se registró de acuerdo con el índice de O'Leary obteniéndose en todos los elementos dentarios a través de la coloración de biopelícula dentaria por solución de fucsina básica a $2 \%$. Para el cálculo del IP se contabilizaron las superficies dentarias (caras) presentes en la cavidad oral, con excepción de las superficies incisivas y oclusivas. El mismo procedimiento fue adoptado para la determinación del índice gingival (IG) siendo contabilizadas las superficies dentarias que presentaron sangrado tras sondeo.

Tras la etapa clínica se realizó el examen bioquímico que consistió en la recolocación de sangre periférica para la determinación del valor de la proteína C-reactiva ultrasensible (PCR-US). También se solicitó un hemograma completo con el objetivo de averiguar si en el momento de la evaluación de la PCR-US hubiera algún cuadro que sugiriese proceso infeccioso y/o inflamatorio.

La recolección sanguínea se realizó en la propia institución de enseñanza donde se realizó la investigación, siempre en el horario de las 08:00 horas de la mañana, con los participantes previamente orientados a estar en ayunas al menos en las 4 horas previas al examen. Para tal procedimiento se recolectaron $10 \mathrm{~mL}$ de sangre periférica, proveniente de venas cubitales.

Para la realización del hemograma, la sangre recogida fue depositada en tubos con EDTA para evitar su coagulación, y procesada de forma computarizada, con eventual estudio morfológico en frotis coloreados. Para el examen de la proteína C-reactiva fue realizada la colecta de sangre total y tras la coagulación sanguínea y retracción del coágulo, el suero fue debidamente separado y procesado, siendo el método de análisis la imunonefelemotria.

Tras la toma de los datos los participantes recibieron instrucción y motivación hacia la higiene oral y fueron sometidos a profilaxis dentaria y aplicación tópica de flúor. Los participantes del grupo con enfermedad periodontal fueron encaminados hacia el tratamiento periodontal.
Previamente al análisis estadístico de los datos recogidos se realizó la exclusión de 02 (dos) participantes por presentar alteraciones en el leucograma (serie blanca). Ese criterio fue adoptado con el objetivo de descartar infecciones de otra naturaleza que pudiesen manifestarse de forma subclínica sin evidenciar señales y/o síntomas. Fueron eliminados del experimento los participantes que presentaron un cómputo total de leucocitos encima de 10.000 células por mililitro cúbico (leucocitosis).

Todos los participantes seleccionados recibieron un formulario de consentimiento libre, en el cual constan todas las informaciones al respecto de la investigación, procedimientos a los que habían sido sometidos, así como sus derechos como participantes, demostrando su participación voluntaria en el estudio. La investigación fue aprobada por el Comité de Ética en investigación de la Universidad Federal de Río Grande do Norte, resolución 196/1996-CSN, protocolo número 120/05.

De entre las variables analizadas en el estudio, la proteína C-reactiva fue clasificada como variable dependiente y como independientes fueron la enfermedad periodontal, sexo, edad, renta familiar, escolaridad, recesión gingival, profundidad de sondeo, nivel de inserción, movilidad dentaria, mucosa queratinizada, índice gingival e índice de placa.

Para la realización del análisis estadística fueron dicotomizadas todas las variables independientes. La categorización para la variable edad se realizó de acuerdo con la mediana encontrada. El procedimiento se realizó con el intento de promover una mayor homogeneidad entre esos datos. La variable edad dicotomizada a partir de la mediana (36 años), y fue representada por las categorías abajo o igual a 36 años y encima de 36 años. Con respecto a la renta familiar, la misma fue categorizada en menor o igual la 5 SM y encima de $5 \mathrm{SM}$, y la escolaridad hasta el $2^{\circ}$ grado completo y superior al $3^{\circ}$ grado.

En el análisis estadístico entre la variable dependiente (PCR-US) y la variable independiente principal (enfermedad periodontal) fue realizada empleando el test t de Student. El nivel de acepción utilizado fue de $5 \%$. Para la verificación de la normalidad de los datos se empleó el test de Kolmogorov-Smirnov.

Para la clasificación del riesgo de desarrollo de enfermedades cardiovasculares y debido al tamaño de la muestra se optó por utilizar el Test exacto de Fisher 
con el propósito de comparar proporcionalmente los datos obtenidos. De esa forma, la proteína C-reactiva fue categorizada en dos grupos de acuerdo con el riesgo de desarrollo de enfermedades cardiovasculares, con lo que pacientes portadores de niveles séricos de PCR mayor que $0,3 \mathrm{mg} / \mathrm{dL}$ se clasificaron como de alto riesgo y aquellos con niveles menores que $0,3 \mathrm{mg} / \mathrm{dL}$ de bajo riesgo de desarrollo de enfermedades cardiovasculares. También se empleó la odds ratio (OR) como medida de asociación y riesgo entre la enfermedad periodontal y la PCR-US.

Las variables intervinientes fueron divididas en variables intervinientes socio-demográficas y variables intervinientes clínicas. Para el análisis de las variables socio-demográficas (sexo, edad, renta y escolaridad) frente a la variable dependiente (PCR-US) fue utilizado el test t de Student para comparar medias entre esas variables. Las variables intervinientes clínicas (recesión gingival, profundidad de sondeo, nivel de inserción, movilidad dentaria, encía ceratinizada, índice gingival e índice de placa) se analizaron por correlación bivariada utilizando el coeficiente de correlación de Spearman para indicar la fuerza de asociación entre las variables y la PCR-US.

\section{RESULTADOS}

\section{Caracterización de la muestra}

La caracterización de la muestra puede ser observado en tabla 1.

\section{Asociación entre niveles de PCR-US y enfermedad periodontal}

Los dados de la estadística descriptiva y los otros que relacionan "concentración de PCR-US" con la variable independiente principal "enfermedad periodontal" pueden ser observados en tabla 2.

\section{Clasificación del riesgo cardiovascular}

Para esa análisis, la variable dependiente PCR-US fue categorizada de acuerdo con el riesgo cardiovascular en alto riesgo cuando los valores encontrados para la PCR-US fueron superiores la $0,3 \mathrm{mg} / \mathrm{dl}$ y en bajo riesgo cuando los valores obtenidos se presentaron infe-

\section{TABLA 1.- CARACTERIZACIÓN DE LA MUESTRA. NATAL, RN. 2008}

\begin{tabular}{|c|c|c|c|c|c|c|}
\hline \multirow[t]{2}{*}{ Variable } & \multicolumn{2}{|c|}{ Grupo I } & \multicolumn{2}{|c|}{ Grupo II } & \multicolumn{2}{|c|}{ Total } \\
\hline & & $(\%)$ & & $(\%)$ & $\mathbf{n}$ & $(\%)$ \\
\hline & 29 & $(48,3)$ & 31 & $(51,7)$ & 60 & (100) \\
\hline \multicolumn{7}{|l|}{ SEXO } \\
\hline - Masculino & 10 & $(45,4)$ & 12 & $(54,6)$ & 22 & (100) \\
\hline - Femenino & 19 & $(50,0)$ & 19 & $(50,0)$ & 38 & $(100)$ \\
\hline \multicolumn{7}{|l|}{ EDAD } \\
\hline - $<36$ años & 15 & $(48,4)$ & 16 & $(51,6)$ & 31 & (100) \\
\hline - > 36 años & 14 & $(48,3)$ & 15 & $(51,7)$ & 29 & (100) \\
\hline \multicolumn{7}{|l|}{ RENTA } \\
\hline - $<5 \mathrm{SM}$ & 07 & $(50,0)$ & 07 & $(50,0)$ & 14 & (100) \\
\hline - $>5 \mathrm{SM}$ & 22 & $(47,8)$ & 24 & $(52,2)$ & 46 & (100) \\
\hline \multicolumn{7}{|l|}{ ESCOLARIDAD } \\
\hline - Hasta $2^{\circ}$ grado completo & 20 & $(76,9)$ & 06 & $(23,1)$ & 26 & (100) \\
\hline - $3^{\circ}$ grado o más & 09 & $(26,5)$ & 25 & $(73,5)$ & 34 & (100) \\
\hline
\end{tabular}




\begin{tabular}{|c|c|c|c|c|c|c|}
\hline \multicolumn{7}{|c|}{$\begin{array}{c}\text { TABLA 2.- ESTADÍSTICA DESCRIPTIVA DE LA CONCENTRACIÓN DE PCR-US, } \\
\text { VALORES DEL TEST T Y ACEPCIÓN ENTRE LOS GRUPOS CON Y SIN ENFERIMEDAD } \\
\text { PERIODONTAL. NATAL, RN. } 2008\end{array}$} \\
\hline Grupo & $\mathbf{n}$ & Media & $\pm \mathbf{D P}$ & IC (95\%) & Test $t$ & $\mathbf{p}$ \\
\hline Con enfermedad & 29 & 0,36 & 0,56 & $0,16-0,76$ & \multirow{2}{*}{1,908} & \multirow{2}{*}{0,061} \\
\hline Sin enfermedad & 31 & 0,17 & 0,13 & $0,12-0,18$ & & \\
\hline Total & 60 & 0,27 & 0,41 & $0,10-0,51$ & 1,098 & 0,061 \\
\hline
\end{tabular}

riores a 0,3 mg/dl de acuerdo con Asociación Americana del Corazón (2003).

De esa forma, un total de $27,6 \%$ de los participantes con enfermedad periodontal fueron clasificados como de alto riesgo de desarrollo de enfermedades cardiovasculares y $72,4 \%$ como de bajo riesgo. En relación a los pacientes sin enfermedad periodontal, $6,45 \%$ presentaron alto riesgo y $93,5 \%$ bajo riesgo de desarrollo de enfermedades cardiovasculares, siendo esa asociación significativa, presentando valor de $p=0,042$, de acuerdo con lo observado en la tabla 3.

En la tabla 3 también puede ser visualizada la razón de probabilidad (odds ratio) calculada con el objetivo de estimar el riesgo, es decir para estimar la fuerza de la asociación existente entre la PCR-US y la enfermedad periodontal. El odds ratio (OR) indica que la enfermedad periodontal actúa como factor asociado para la elevación de los niveles plasmáticos de la proteína C-reactiva, sin embargo presenta una frágil aso- ciación debido a la gran amplitud del intervalo de confianza.

\section{Análisis estadística de las variables intervinientes}

Las otras variables analizadas en el presente estudio fueron las denominadas variables intervinientes, así designadas por presentar potencial para influenciar u ocasionar alteraciones en las concentraciones séricas de la PCR-US. El análisis estadístico de las referidas variables se dividió en análisis de las variables intervinientes socio-demográficas y las relacionadas a los cuadros clínicos denominadas variables interventores clínicas.

Las variables intervinientes socio-demográficas analizadas fueron el sexo, la edad, la renta familiar y la escolaridad. Las variables referidas pueden ser observadas en la tabla 4 que presenta la estadística descriptiva de cada una de las variables en relación al

\section{TABLA 3.- RELACIÓN ESTADÍSTICA ENTRE LOS GRUPOS ESTUDIADOS Y EL RIESGO CARDIOVASCULAR. NAVIDAD, RN. 2008}

\begin{tabular}{|c|c|c|c|c|c|}
\hline \multirow[t]{3}{*}{ Grupo } & \multicolumn{3}{|c|}{ PCR Riesgo } & \multirow[t]{3}{*}{ p* } & \multirow[t]{3}{*}{ OR (IC95\%) } \\
\hline & \multicolumn{2}{|r|}{ Bajo } & Alto & & \\
\hline & $\mathbf{n}$ & $(\%)$ & $(\%)$ & & \\
\hline Con enfermedad periodontal & 21 & $(72,4 \%)$ & $08(27,6 \%)$ & 0,042 & $5,33(1,02-27,75)$ \\
\hline Sin enfermedad periodontal & 29 & $(93,5 \%)$ & $02(6,45 \%)$ & & \\
\hline
\end{tabular}

* Probabilidad para el test Exacto de Fisher. 


\section{TABLA 4.- ESTADÍSTICA DESCRIPTIVA DE LA CONCENTRACIÓN DE PCR-US, VALORES DEL TEST T Y ACEPCIÓN PARA LAS VARIABLES INTERVINIENTES SOCIO-DEMOGRÁFICÂS ANALIZADASS EN EL ESTUDIO. NATAL, RN. 2008}

\begin{tabular}{|c|c|c|c|c|c|c|}
\hline Variable & $\mathbf{n}$ & Media & $\pm \mathbf{D P}$ & IC (95\%) & Test $\mathbf{t}$ & $\mathbf{p}$ \\
\hline \multicolumn{7}{|l|}{ SEXO } \\
\hline $\begin{array}{l}\text { - Masculino } \\
\text { - Femenino }\end{array}$ & $\begin{array}{l}22 \\
38\end{array}$ & $\begin{array}{l}0,18 \\
0,32\end{array}$ & $\begin{array}{l}0,26 \\
0,47\end{array}$ & $\begin{array}{l}0,07-0,38 \\
0,17-0,61\end{array}$ & \multirow[t]{2}{*}{$-1,310$} & \multirow[t]{2}{*}{0,195} \\
\hline Total & 60 & 0,27 & 0,41 & $0,16-0,51$ & & \\
\hline \multicolumn{7}{|l|}{ EDAD } \\
\hline $\begin{array}{l}\cdot<36 \text { anos } \\
\cdot>36 \text { anos }\end{array}$ & $\begin{array}{l}31 \\
29\end{array}$ & $\begin{array}{l}0,26 \\
0,27\end{array}$ & $\begin{array}{l}0,43 \\
0,40\end{array}$ & $\begin{array}{l}0,11-0,57 \\
0,13-0,54\end{array}$ & \multirow[t]{2}{*}{$-0,073$} & \multirow[t]{2}{*}{0,942} \\
\hline Total & 60 & 0,27 & 0,41 & $0,16-0,51$ & & \\
\hline \multicolumn{7}{|l|}{ RENTA } \\
\hline $\begin{array}{l}\bullet<5 \mathrm{SM} \\
\cdot>5 \mathrm{SM}\end{array}$ & $\begin{array}{l}14 \\
46\end{array}$ & $\begin{array}{l}0,20 \\
0,29\end{array}$ & $\begin{array}{l}0,24 \\
0,45\end{array}$ & $\begin{array}{l}0,07-0,37 \\
0,16-0,58\end{array}$ & \multirow[t]{2}{*}{$-0,719$} & \multirow[t]{2}{*}{0,475} \\
\hline Total & 60 & 0,27 & 0,41 & $0,16-0,51$ & & \\
\hline \multicolumn{7}{|l|}{ ESCOLARIDAD } \\
\hline $\begin{array}{l}\text { - Hasta } 2^{\circ} \text { grado completo } \\
\text { - } 3^{\circ} \text { grado o más }\end{array}$ & $\begin{array}{l}26 \\
34\end{array}$ & $\begin{array}{l}0,18 \\
0,33\end{array}$ & $\begin{array}{l}0,22 \\
0,50\end{array}$ & $\begin{array}{l}0,10-0,30 \\
0,16-0,67\end{array}$ & \multirow[t]{2}{*}{$-1,455$} & \multirow[t]{2}{*}{0,151} \\
\hline Total & 60 & 0,27 & 0,41 & $0,16-0,51$ & & \\
\hline
\end{tabular}

desenlace, la variable concentración sérica de PCRUS. El test estadístico empleado para evaluar la relación de estas variables intervinientes con PCR-US fue el test t de Student.

Se puede observar que las variables intervinientes citadas no presentaron influencia sobre el desenlace del estudio, es decir, no ocasionaron interferencias en los niveles séricos de la proteína C-reactiva.

Las variables intervinientes clínicas analizadas fueron las medidas de recesión gingival $(r=-0,52, p=0,698)$, profundidad de sondeo $(r=0,038, p=0,772)$, nivel de inserción periodontal ( $r=-0,020, p=0,882)$, encía queratinizada $(r=-0,102, p=0,443)$, movilidad dentaria $(r=-0,23$, $\mathrm{p}=0,864)$, índice gingival $(\mathrm{r}=0,123, \mathrm{p}=0,363)$ e índice de placa $(r=0,147, p=0,267)$. Como se tratan de variables cuantitativas que no siguen una distribución normal, se empleó la correlación de Spearman con el objetivo de verificar la existencia y/o caracterización de la relación entre estas variables y la PCR-US. Sin embargo, se observó que las variables no se correlacionan entre sí.
A la luz de los resultados obtenidos se observa que las variables intervinientes analizadas en el estudio, tanto las variables socio-demográficas como las clínicas, no poseen el poder de interferir sobre los niveles séricos de proteína C-reactiva ultrasensible.

\section{DISCUSIÓN}

No se encuentra totalmente aclarado el papel de la proteína C-reactiva en la periodontitis, sin embargo algunos trabajos $(11,16,23,24)$ intentan desvelar una posible relación entre la inflamación crónica, mediadores inflamatorios e imunológicos provenientes de la enfermedad periodontal con el aumento del riesgo de enfermedades cardiovasculares.

La proteína C-reactiva puede considerarse como un importante marcador de estados inflamatorios, evidenciados sobre todo en cuadros inflamatorios agudos, y también se pueden encontrar niveles alterados en estados crónicos (25). El proceso patogénico de la en- 
fermedad periodontal es complejo, y es sabido que la infección y la inflamación constituyen marcos fundamentales de ese proceso. La periodontitis genera bacteriemias y estimula la producción de factores como TNF- $\alpha$ y la interleuquina- 6 , que presentan la capacidad de estimular a las células hepáticas a producción de proteína C-reactiva. De esa forma se espera encontrar niveles séricos más elevados de PCR en la vigencia de la enfermedad periodontal $(17,26)$.

Estudiando los resultados obtenidos, el grupo de pacientes con enfermedad periodontal crónica severa generalizada presentó un promedio de la concentración sérica de PCR-US mayor que el del grupo sin enfermedad periodontal, aunque la diferencia entre esas medias sea destacable, no existió una relación estadísticamente significativa.

Sin embargo, existe una cierta tendencia y probabilidad a que estos valores presenten una relevancia estadística debido a la proximidad con los valores de acepción. Así, el resultado de la comparación entre las medias puede estar enmascarado por el número de individuos que fueron seleccionados para el estudio, necesitando hacer una expansión de la muestra en futuras investigaciones. La muestra de este experimento fue resultado del bajo índice de individuos portadores de enfermedad periodontal, en el caso periodontitis crónica severa generalizada, ausentes de manifestaciones o condiciones sistémicas. Individuos portadores de tales condiciones no fueron seleccionados para el experimento porque las alteraciones sistémicas pudieran interferir sobre los niveles séricos de la proteína C-reactiva, enmascarando solamente el efecto de la enfermedad periodontal sobre la PCR.

Estudios en la literatura apuntan un aumento estadísticamente significativo de los niveles séricos de proteína C-reactiva al comparar pacientes con y sin enfermedad periodontal, como lo observado en los experimentos de Ebersole y colaboradores (25) que utilizaron una muestra de 96 pacientes y el de Loos y colaboradores (13) al analizar un universo de 107 individuos.

Noack y colaboradores (2) en un estudio contiendo 174 individuos, también constataron una elevación de los niveles de PCR en los pacientes que presentaban enfermedad periodontal, sin embargo esa elevación parece estar en dependencia con la severidad de la enfermedad y con la presencia de patógenos periodontales. Sin embargo, Matilla y colaboradores (23), al evaluar a 35 pacientes, observaron que los niveles de esa proteína parecen elevar sólo en algunos individuos con periodontitis.
De la misma forma, en el presente estudio se observó que los niveles de PCR estaban alterados solamente en algunos individuos portadores de enfermedad periodontal. Beck y Offenbacher (27) justifican esa ocurrencia basados en evidencias genéticas en las que algunas personas pueden presentar un fenotipo hiperinflamatorio, es decir, pueden responder exacerbadamente a un estímulo inflamatorio, estímulo este ocasionado por la enfermedad periodontal.

Por otro lado, Slade y colaboradores (24) constataron que individuos con enfermedad periodontal y pacientes edentados, poseyeron los mismos niveles de PCRUS, cuando se analizaban individuos de la misma edad. Así, corroboran Beck y Offenbacher (27) al sugerir que pacientes que presentan niveles más elevados de PCRUS tienen, en realidad, una tendencia genética a una hiperactividad inflamatoria. Asimismo, tanto la periodontitis como cualquier otra enfermedad capaz de promover un cuadro inflamatorio pueden ocasionar un aumento en los niveles de PCR-US.

Algunos estudios $(2,16,28)$ apuntan como una gran dificultad y también como limitación la existencia de diversos factores potencialmente capaces de ocasionar alteraciones en los niveles séricos de PCR-US. De esa forma, cualquier factor que actúe directa o indirectamente en el organismo promoviendo algún proceso inflamatorio sea factible de ocasionar alteraciones en los niveles de PCR-US. Además a esta etiología multifactorial se suma la existencia de una variabilidad biológica individual en la cuantificación plasmática de la proteína C-reactiva $(4,13,29)$.

La proteína C-reactiva ultrasensible se señala en la literatura como un marcador inflamatorio validado como predictor de riesgo cardiovascular. Basado en la publicación Asociación Americana del Corazón y del Centro para Controle de las Enfermedades en 2003, las concentraciones plasmáticas de PCR-US obtenidas por debajo de $0,1 \mathrm{mg} / \mathrm{dL}$ son consideradas de bajo riesgo de desarrollo de enfermedades cardiovasculares, mientras concentraciones variando entre $0,1-0,3 \mathrm{mg} / \mathrm{dL}$ son consideradas de mediano riesgo. Concentraciones mayores que $0,3 \mathrm{mg} / \mathrm{dL}$ se asocian con un mayor riesgo de desarrollo de enfermedades cardiovasculares siendo considerada la concentración de $0,3 \mathrm{mg} / \mathrm{dL}$ el punto de corte para definir individuos de alto riesgo cardiovascular (11). A la luz de los resultados obtenidos, la concentración promedio de PCR-US encontrada en el presente estudio para los pacientes con enfermedad periodontal fue de $0,36 \mathrm{mg} / \mathrm{dL}$, mientras que en los individuos sin enfermedad periodontal esa concentra- 
ción presentó una media de 0,17 mg/dL. El riesgo de predicción de desarrollo de enfermedades cardiovasculares se consideró alto para grupos con enfermedad y mediano para el sin enfermedad periodontal.

En lo que se refiere al grupo compuesto por pacientes con enfermedad periodontal, cerca del $27,6 \%$ de los individuos fueron clasificados como de alto riesgo cardiovascular y $72,4 \%$ como de bajo o mediano riesgo presentando una asociación significativa con la enfermedad cardiovascular. Como la enfermedad periodontal ocurre en irrupciones de actividad y períodos de remisión, es probable que los individuos con niveles plasmáticos de proteína C-reactiva mayores que 0,3 $\mathrm{mg} / \mathrm{dL}$ se encuentren con mayores grados de actividad inflamatoria ocasionadas por la enfermedad, y los clasificados como de bajo riesgo probablemente en el periodo de remisión. Otro justificante para las altas concentraciones se condicionan por el fenotipo hiperinflamatorio que puedan presentar esos individuos. Existe también la posibilidad de que el alto riesgo cardiovascular sea proveniente de la presencia de enfermedades, alteraciones o condiciones sistémicas que se manifiestan de forma subclínica generando un cuadro inflamatorio que no fueron identificadas por los participantes.

Estas evidencias también pueden justificar la presencia de dos (02) participantes sin enfermedad periodontal presenten niveles séricos de PCR-US mayores que $0,3 \mathrm{mg} / \mathrm{dL}$ siendo clasificados como de alto riesgo cardiovascular. Esos individuos, probablemente, podrían estar presentando en el momento del examen un cuadro inflamatorio y/o infeccioso no evidenciados clínicamente o que no habían sido detectados por el hemograma.

Los datos encontrados indican que la enfermedad periodontal puede considerarse un factor asociado para el aumento de los niveles séricos de PCR-US, sin embargo, de frágil asociación, ya que es grande la diferencia existente entre el límite superior $(1,02)$ e inferior $(27,75)$ del intervalo de confianza.

D'aiuto y colaboradores (11) al evaluar el efecto del tratamiento periodontal no quirúrgico sobre los niveles de PCR-US constataron que, previamente al tratamiento, los niveles de PCR-US eran elevados suficientemente para ser encuadrados como de mediano y alto riesgo de desarrollo de enfermedades cardiovasculares, concordando, así, con los parámetros establecidos por Asociación Americana del Corazón y del Centro para Controle de las Enfermedades. Así, concluyeron que la terapia periodontal promueve una reducción de los niveles de PCR-US asociada a la reducción del riesgo cardiovascular. Sin embargo, los autores sugieren la necesidad de estudios de amplia escala para asegurar positivamente esa relación.

En contrapartida Yamasaki y colaboradores (15) también, en estudio similar, no observaron reducción significativa de la inflamación sistémica tras el tratamiento periodontal. Todavía en ese estudio los autores no encontraron relación entre la severidad de la enfermedad periodontal y los niveles de PCR, concluyendo que la enfermedad periodontal no afecta, de forma significativa, las concentraciones séricas de los marcadores sistémicos de la inflamación. Los autores también sugieren la realización de nuevas investigaciones con muestras mayores para intentar dilucidar la influencia de la enfermedad periodontal sobre la inflamación sistémica.

Al analizar las variables intervinientes determinadas como posibles de ocasionar interferencias sobre los niveles séricos de la proteína C-reactiva se observó que tanto las variables consideradas como sociodemográficas como las variables clínicas no presentaron potencial de interferir sobre los valores plasmáticos de la PCR-US, debido a no existencia de una relación estadísticamente significativa entre las variables independientes y dependiente.

La selección de los pacientes de cada grupo, teniendo por base la edad y el sexo, se realizó con la finalidad de intentar minimizar otros posibles factores externos que pudieran interferir en los niveles serios de PCRUS. Así, se observó que tanto el sexo como las edades analizadas no presentaron efecto suficiente para interferir en los niveles séricos de proteína C-reactiva, lo que constató la importancia de su realización, a pesar de que la concentración sérica de PCR-US tiende a ser mayor en el sexo femenino. Esa diferencia no es estadísticamente significante, lo que explica la no interferencia de esa variable en las concentraciones de PCRUS. De acuerdo con Woloshin y Schwartz (4) existe una cierta tendencia a que las mujeres presenten niveles de PCR mayores que los hombres. Sin embargo, la causa probable de esa elevación no ha sido aclarada aún.

Con respecto las edades analizadas, se han encontrado medias de concentraciones de PCR-US prácticamente semejantes. Sin embargo, se sabe que con el aumento de la edad puede ocurrir también un aumento en los niveles de PCR debido al aumento de la acumulación de grasa corporal, sedentarismo y debido al 
aumento de la incidencia de patologías subclínicas las cuales poseen componentes inflamatorios (26). Quizás esa elevación no haya sido evidenciada debido a que la franja de edad comprendida en el estudio ha sido de 19 a 56 años.

Las demás variables socio-demográficas analizadas que incluyen la franja de renta familiar y el grado de escolaridad tampoco presentaron resultados estadísticamente significativos en relación con las concentraciones séricas de proteína C-reactiva. De esa forma, podemos constatar que las variables citadas no interfieren en los niveles de proteína C-reactiva demostrando un carácter homogéneo de la muestra.

Se hace pertinente observar que algunas condiciones relacionadas como factores socioeconómicos y bajo grado de escolaridad están relacionados con una menor expectativa y condición de vida, así puede ocurrir que niveles plasmáticos más elevados de PCR sean encontrados en esas condiciones (5).

Con respecto a las variables intervinientes clínicas responsables del diagnóstico y encuadramiento de los participantes en los grupos estudiados, se observó que las variables clínicas no se correlacionan a los niveles plasmáticos de PCR-US. Los datos demuestran que ninguna de las variables analizadas presentaba un efecto mayor sobre las demás variables, influenciando, marcantemente, la concentración de la proteína Creactiva. Las características clínicas evaluadas por estas variables comprenden el conjunto responsable por el efecto inflamatorio de la enfermedad periodontal.

No existe un consenso en la literatura sobre el hecho de que la proteína C-reactiva pueda considerarse como un factor determinante de la relación entre la enfermedad periodontal y el riesgo de desarrollo de enfermedades cardiovasculares. Por lo tanto, se hace necesario que se realicen estudios a gran escala con el objetivo de averiguar con más precisión la relación entre la enfermedad periodontal y la cardiovascular. Pueden ser empleados estudios de carácter longitudinal para ver la predisposición en el riesgo de desarrollo de cardiopatías en pacientes portadores de enfermedad periodontal, a través de cortes y casos de control. Además, son escasos todavía los estudios que realmente establecen el papel de la proteína C-reactiva en la enfermedad periodontal, necesitando que más investigaciones sobre todo en los casos en los que no sólo la enfermedad periodontal está presente y cuando son evidenciados varios otros factores de riesgo hacia las enfermedades cardiovasculares. Esos estu- dios son necesarios para determinar en que extensión el tratamiento de la enfermedad periodontal puede reducir el agravamiento o incluso la incidencia de eventos cardiovasculares.

Los pacientes portadores de periodontitis crónica severa generalizada no presentaron niveles séricos de proteína C-reactiva ultrasensible estadísticamente diferente de los pacientes sin enfermedad. La periodontitis actuó como factor asociado para la elevación de los niveles plasmáticos de la PCR-US, aunque con frágil asociación.

\section{BIBLIOGRAFÍA}

1. Herzberg MC, Weyer MW. Dental plaque, platelet, and cardiovascular disease. Ann Periodontol 1998;3 (1):15160.

2. Noack B, Genco RJ, Trevisan M. Periodontal Infections Contribuite to Elevated Systemic C-Reative Protein Level. J Periodont 2001;72:1221-7.

3. Pearson TA, Mensah GA, Alexander RW, Anderson JL, Cannon RO, Criqui M, Fadl YY, Fortmann SP, Hong Y, Myers GL, Rifai N, Smith SC, Taubert K, Tracy RP, Vinicor F. Markers of inflammation and cardiovascular disease: application to clinical and public health practice: a Statement for Healthcare Professionals From the Centers for Disease Control and Prevention and the American Heart Association. Circulation 2003;107:499-51 1.

4. Woloshin S, Schwartz LM. Distribution of C-reactive protein values in the United States. N Engl J Med 2005; 352:1611-3.

5. Armitage GC. Periodontal infections and cardiovascular disease - how strong is the association. Oral Disease 2000;6:335-50.

6. Mustapha IZ, Debrey S, Oladubu M, Ugarte R. Markers of systemic bacterial exposure in periodontal disease and cardiovascular disease risk: a systematic review and meta-analysis. J Periodontol 2007;78(12):2289-302.

7. Xia D, Samols D. Transgenic mice expressing rabbit Creactive protein are resistant to endotoxemia. Proc Natl Acad Sci U S A 1997;94(6):2575-80.

8. Corrêa CR, Burini CR. Proteínas plasmáticas reativas positivas à fase aguda. Jornal Brasileiro de Reumatologia 2000;36:26-34. 
9. Williams RC, Offenbacher S. Periodontal medicine: the emergency of a new branch of Periodontology. Periodontology 2000;23:9-12.

10. Czerniuk MR, Górska R, Filipiak KJ, Opolski G. Creactive protein in patients with coexistente periodontal disease and acute coronary syndromes. J Clin Periodontol 2006;33:415-20.

11. D'Aiuto F, Ready D, Tonetti MS. Periodontal disease and C-reactive protein - associated cardiovascular disease. J Periodontol Res 2004;39:236-41.

12. Elter JR, Hinderliter $\mathrm{AL}$, Offebancher S, Beck JD, Caughey M, Brodala N, Madianos PN. The effects of periodontal therapy on vascular endothelial function: a pilot trial. Revista 2006;151(1):47.

13. Loos BG, Craandijk J, Hoek FJ. Elevatios systemic markers related to cardiovascular diseases in the peripheral blood of periodontitis patients. J Periodontol 2000;71(10):1528-34.

14. Santos WB, Mesquita E T, Vieira RMR, Olej B, Coutinho M, Avezum A. Proteína-C-Reativa e Doença Cardiovascular: As Bases da Evidência Científica. Arq Bras Cardiol 2003;80(4):45-9.

15. Yamazaki K, Honda T, Oda T, Ueki-Maruyama K, Nakajima T, Yoshie H, Seymour GJ. Effect of periodontal treatment on the C-reactive protein and proinflammatory cytokine levels in Japanese periodontitis patients. J Periodont Res 2005;40:53-8.

16. D'Aiuto F, Casas JP, Shah T, Humphries SE, Hingorani AD, Tonetti MS. C-reactive (+1444C>T) polymorphism influences CRP response following a moderate inflammatory stimulus. Atherosclerosis 2005;179:413-7.

17. Ebersole JL, Cappelli D. Acute-phase reactants in infections and inflammatory diseases. Periodontology 2000;23:19-49.

18. Garlet GP, Cardoso CR, Campanelli AP, Ferreira BR, Avila-Campos MJ, Cunha FQ, Silva JS. The dual role of p55 tumor necrosis factor-alpha receptor in Actinobacillus actinomycetemcomitans-induced experimental periodontitis: host protection and tissue destrction. Revista 2007;147(1):128-38.

19. Amabile N, Susini G, Pettenati-Soubayroux I, Bonello L, Gil JM, Arques S, et al. Severity of periodontal disease correlates to inflammatory systemic status and independently predicts the presence and angiographic extent of stable coronary artery disease. J Intern Med 2008;263(6):644-52.

20. Dasanayke AP. Poor periodontal health of the pregnant woman as a risk factor for low birth weigth. Annals of Periodontology 1998;3:206-12.

21. Moutsopoulos NM, Madianos PN. Low-grade inflammation in chronic infectious diseases: paradigm of periodontal infections 2006;1088:251-64.

22. Kinane FD, Lindhe J. Periodontite crônica. In: Lindhe J, Karring T, Lang NP. Tratado de periodontia clínica e implantologia oral. 4 ed. Rio de Janeiro: Guanabara Koogan; 2005. p. 205-9.

23. Matilla K, Vesanen M, Valtonen V. Effect of treating periodontitis on C-reactive protein levels: a pilot study. BMC Infect Dis 2002;2:30-6.

24. Slade GD, Offenbacher S, Beck JD, Heiss G, Pankow JS. Acute-phase inflammatory response to periodontal disease in the US population. J Dent Res 2000;79:49-57.

25. Ebersole JL, Capelli D, Mott G. Systemic acute phase reactants, C-Reative Protein and Haptoglobin, in adult Periodontitis. Clinical Exp. Immunol 1997;107:347-52.

26. Kinane DF, Riggio MP, Walker KF, MacKenzie D, Shearer B. Bacteremia following periodontal procedures. J Clin Periodontol 2005;32:708-13.

27. Beck JD, Offenbacher S. Oral health and systemic disease: periodontitis and cardiovascular disease. J Dent Educ 1998;62(10):859-70.

28. Persson GR, Pettersson T, Ohisson O, Renvert S. Highsensitivity serum C-reactive protein levels in subjects with or without myocardial infarction or periodontitis. J Clin Periodontol 2005;32:219-24.

29. Ouyang XY. Association between periodontal disease and coronary heart disease. Beijing Da Xue Xue Bao 2008;40(1):112-5.

\section{CORRESPONDENCIA}

\author{
Adriana da Fonte Porto Carreiro \\ Av. Alexandrino de Alencar, 1384/14 \\ Tirol Natal/RN Brasil \\ Cep: 59015-350 \\ E-mail: adrianadafonte@hotmail.com
}


